\title{
LA JUNTA DE REFORMACIÓN DE 1586: TAPADAS, COMEDIAS Y VICIOS CORTESANOS ${ }^{1}$
}

\author{
IGNACIO EZQUERRA REVILLA
}

CEDIS, Universidade Nova de Lisboa

IULCE, Universidad Autónoma de Madrid

Fecha de recepción: diciembre 2011

Fecha de aceptación: febrero 2012

La permanencia del proceso de construcción de un sistema confesionalista durante el reinado de Felipe II propició que las sucesivas formas de gestión ante problemas sociales permanentes perdieran, forzosamente, espontaneidad. Ante la continuidad de las circunstancias que motivaron la indicción de la Junta de Reformación en 1573 y su recuperación en $1579^{2}$, no sorprende que la de 1586 tuviese un aire ya conocido. Pero lo importante de todas ellas fue la importancia fulcral de la reformación de las costumbres públicas en la disputa por la hegemonia en el orbe católico entre la Monarquía Hispana y el Papado. Tradicionalmente, éste era ámbito exclusivo de intervención, más bien de exhibición, del poder espiritual, según detallara Fray Jerónimo Román en sus Repúblicas del Mundo ${ }^{3}$. Pero fue precisamente su ineficacia en la proscripción de

\footnotetext{
1. Trabajo incluido en el proyecto de investigación «Interaction among the castilian and portuguese administrative reformation, after the annexation of 1580», sufragado por la Fundação para a Ciência e a Tecnologia (Ministério da Ciència, Tecnologia e Ensino Superior. República Portuguesa), SFRH/BPD/41300/2007, orientado por Antonio Manuel Hespanha.

2. Ezquerra Revilla, Ignacio, «La reforma de las costumbres en tiempo de Felipe II: las 'Juntas de Reformación' (1574-1583)», en MartíneZ Millán, José (dir.), Felipe II (1527-1598). Europa y la Monarquía Católica, III, Madrid: Editorial Parteluz, 1998, pp. 179-208.

3. RomÁn, Fray Jerónimo, Repúblicas del Mundo. Divididas en tres partes..., Salamanca: Juan Fernández, 1595 (ed. facsímil, A Coruña, 2009), libro Quinto, capítulo XIII: «Del modo y manera que tenía antiguamente la yglesia en dar castigo, y penitencia a los que peccavan públicamente...»: «... Todos los que auían de hazer penitencia pública venían el primer día de Quaresma, a las puertas de la yglesia, y estavan por de fuera puestos de rodillas, y venían vestidos de vestiduras ásperas, y de cilicios, y descalços, tresquilados y postrados en tierra aguardavan al obispo, el qual venido, y sentándonse con su hábito pontifical, preguntava qué querían aquellos hombres allí. Ellos respondían con humildad diziendo que eran peccadores, y
} 
los pecados públicos la que ofreció campo de afirmación al poder temporal, espacio para la construcción de un aparato político cuya fortaleza residía, precisamente, en la interesada tutela de los pasos que en ese sentido daba la Iglesia. Fue una tendencia visible desde fecha temprana, que culminó con la aplicación de los cánones tridentinos, instrumento a partir del cual los poderes temporales se consolidaron mediante la puesta en práctica de una política abiertamente confesionalizadora ${ }^{4}$.

\section{LA REFORMACIÓN ENTRE JORNADAS (1583-85)}

Al regreso de la jornada de Portugal, la reformación de costumbres seguía plenamente vigente como materia para la disputa política cortesana. La iniciativa en su uso continuó correspondiendo al grupo castellanista, a través del secretario Mateo Vázquez, quien, ante la inestabilidad que los episodios de deambulación regia solían provocar en la gestión cortesana, volvió a incitar el miedo providencialista del rey, como forma de mantener un orden social que, en definitiva, era resultado del conjunto de valores defendido por su grupo político. Avanzada ya la década de 1580, era este un rasgo de continuidad que también se evidenció en el recurso por parte del secretario, como autoridad para avalar sus puntos de vista, al doctor Juan Ramírez, un renombrado jesuita al que no entusiasmaba la tendencia monopolística que la Sede Apostólica solía mostrar en materia de reforma de la sociedad ${ }^{5}$.

El 8 de agosto de 1583 Mateo Vázquez se dirigió al rey para revestir de realidad objetiva aquello que no dejaba de ser, convenientemente dramatizado, recurso táctico dirigido a la obtención de un fín concreto. Se mostraba como mero portavoz de un clamor ajeno, cuya entidad le obligaba, inevitable, casi involuntariamente, a reparar en él. Para ello, invocó cómo el padre Ramírez le había llorado duelos del lamentable estado de la Corte en cuanto a observancia social de la moral católica, «... que dize nunca la ha visto tan libre y llana de peccados y abominaciones como agora... $\rangle^{6}$. En su queja, Ramírez deslizaba principios del mencionado universo político, caso de la necesaria implicación de los ministros temporales en la corrección de tal estado de cosas, dado que les consideraba responsables de dejación tanto en la expulsión de los vagabundos de la Corte como en el castigo de los pecados públicos; o el valor ejemplar conferido a ésta en el conjunto de los reinos, dado que mencionó la excusa a la que se solían acoger

que aguardavan penitencia. Estavan allí el Deán y otros clérigos que manifestavan los delitos de cada uno, para que según la graveza del peccado se les aplicasse la penitencia...». Tan humillante ceremonia databa del Concilio Agatense (413) (op. cit., f. 289v.).

4. SCHILling, Heinz, «The reformation and the rise of the early modern state», en TRACY, J.D., Luther and the modern state in Germany, Kirksville, 1986, pp. 21-30, y la aplicación a España de MARTíNEZ MILLÁN, José, «En busca de la ortodoxia: el Inquisidor General Diego de Espinosa», en IDEM, dir., La Corte de Felipe II, Madrid, 1994, pp. 189-228, entre otros trabajos.

5. Su biografía, en QuINTANA, Jerónimo de la, Historia de la antigüedad, nobleza y grandeza de la villa de Madrid, Madrid, 1629 (reed. 1954), pp. 355-364 y MuÑOZ, L., «Sumario de la vida del padre Juan Ramírez», en Sala Balust, Luis (dir.), Vidas del padre maestro Juan de Ávila, Barcelona, 1964, pp. 347-352. 6. AZ (Archivo Zabalburu), c. (carpeta) 142, nº 63. 
los corregidores cuando eran acusados de negligencia en este terreno: la falta de atención al mismo en la propia Corte.

Como de costumbre, el secretario incurrió en el exceso retórico para atraer al rey a su criterio ${ }^{7}$, para, sin solución de continuidad, proponer remedios que, en definitiva, se dirigían a consolidar su propia posición. Su enunciación permite deducir aquellos aspectos que dieron contenido, entonces y en adelante, a la reformación de costumbres, entre los que destacaba aliviar a la Corte de la presión demográfica que propiciaba los referidos excesos. En este sentido, Mateo Vázquez abogó en primer lugar porque los grandes y señores fuesen a sus tierras y estados «... para consolar y hacer just[ici]a y componer a sus vassallos en sus trabajos y differen[ci]as»; en segundo, por advertir a los catarriberas que la permanencia en la Corte en espera de la resolución de sus pretensiones les perjudicaría más que otra cosa; y en último lugar, una propuesta cuya formulación demostraba que, como en las anteriores ocasiones, el enfoque dado al asunto era fundamentalmente represivo, conforme al interés en el disciplinamiento social que regía tan importante ámbito de la política confesionalizadora ${ }^{8}$. Consistía en la provisión de un juez privativo o alcalde específicamente encargado del destierro de vagabundos y la persecución de los pecados públicos.

$\mathrm{Si}$, puesta en relación con las juntas de reformación precedentes, la respuesta real a estas propuestas parecía implicar un regreso al cauce ordinario de gestión de estos asuntos (por vía principalmente del Consejo Real), de cara a la inminente Junta parecía un preludio de su celebración; dado que el rey, entre lamentos por la situación, remitió al doctor Ramírez a dos de sus futuros miembros, cuya función en la Corte les predisponía a su integración en ella. Tales eran el presidente del Consejo Real, máxima autoridad de la jurisdicción temporal de la que dependería la materialización de los acuerdos adoptados, y el confesor, fray Diego de Chaves, cuyo ascendiente sobre la conciencia regia resultaba sumamente operativo en la resolución de esta clase de asuntos. Como decía el propio rey, «... son de los q. más podrán ayudar al remedio dello...», y esto con particularidad adaptada a la realidad concreta de los diferentes aspectos de la materia, y no a una cualidad que siempre terminaba desembocando en su distorsión. Coherente con ello fue el apoyo especial de Felipe II al tercer punto propuesto por el secretario, que reflejaba la prioridad que confería a un expediente regular de los asuntos, al afirmar que «a los al[ca]ldes conuendrá mucho ordenar que hagan lo q. deuen a sus oficios y si no quitarlos». Sólo la realidad del despacho obligaba a adop-

7. Ibidem, «... El peccado de la carne dizen q anda tan suelto entre gente principal y honrrada q no se occupan mucho las rameras... en fin dize Ramírez q la just[ici]a no procede tan entera y diligente como es menester, si no tan floxa y remissam[en]te q. falta, lo que puede poner gran temor, porque faltando la de la tierra, vendrá la del cielo sobre todo esto, y castigarnos ha Dios q si tarda, sabemos q recompensa la tardança con la gravedad del castigo»».

8. Po ChIA-Hsia, R., Social Discipline in the reformation: Central Europe 1550-1750, Padstow, 1989, pp. 1-9; KRIEKEN, Robert van, «Social discipline and State formation: Weber and Oestreich on the historical sociology of subjectivity», Amsterdams Sociologisch Tijdschrift 17-1 (1990) pp. 3-28; PRODI, Paolo, dir., Disciplina dell'anima, disciplina del corpo e disciplina della Societá tra medioevo ed etá moderna, Bolonia, 1994. 
tar expedientes alternativos, $\mathrm{y}$, conforme a ello, el rey anticipaba la celebración de la próxima junta: «... creo se podría tener alguna junta sobre estas cosas y acordareismelo $\mathrm{p}[\mathrm{ar}] \mathrm{a}$ q. ueamos cómo y con quién» ${ }^{9}$.

La necesidad de una renovada Junta de Reformación parece quedar entonces planteada, pero por el momento no se apreció una variación en el despacho de estos asuntos. Seguía diligenciado de un modo ejecutivo, a través de los alcaldes de Casa y Corte $^{10}$. El rey centró su atención en otros aspectos complementarios, como la falta de doctrina de obispos y sacerdotes, en materia propicia para el roce con Roma. En ello trascendió la vocación confesionalista propia del rey, tanto como la impulsada por el dominio político castellanista. Y quedó confirmada la extensa responsabilidad de Fray Diego de Chaves en cuestiones de reforma de costumbres, así como la aparición de García de Loaysa en ellas, quien iría adquiriendo cada vez mayor intervención tanto en este campo como en el estrictamente político. Ambos trataron de la materia en el verano de 1584, concluyendo que el defecto no era general, sino muy concreto, por lo que, para evitar la nota que para los obispos supondría un escrito canalizado a través del secretario de la Cámara, bastaba la represión particular del confesor Chaves; a quien se tenía auténtico pavor en el medio eclesiástico, conocida como era su rígida condición y el influjo que disfrutaba sobre la conciencia real ${ }^{11}$. Con tales actores, se advertía la operatividad de la conciencia regia en sistemas políticos cuya viabilidad se fundaba, por lo menos en un sentido argumental, en la atracción del favor divino ${ }^{12}$. Si el confesor operaba directamente sobre la conducta real, el capellán y limosnero mayor actuaba de forma más indirecta, propiciando una actitud favorable de la providencia tanto en el terreno formal, mediante plegarias, como en el material, mediante el ejercicio de la caridad. En este último sentido, para auspiciar esta dinámica, era necesaria la visibilidad social del pobre y el vagabundo, obstáculo para un más temprano desarrollo de una consideración económica y productiva en la reforma social, antes que providencialista. Como ha estudiado Michel Cavillac, estas ideas, insinuadas en el caso de Miguel Giginta ${ }^{13}$, no serían enunciadas con mayor claridad hasta el Amparo de pobres, del doctor Pérez de Herrera ${ }^{14}$, y culminadas en el terreno de la creación literaria con

9. AZ, c. $142, \mathrm{n}^{\circ} 63$.

10. EZQUERRA REVILLA, Ignacio, «La reforma de las costumbres en tiempo de Felipe II....», esp. pp. 192193.

11. IVDJ (Instituto Valencia de don Juan), e. (envío) 100, c. (caja) 141, f. 9r.-v.

12. .PizARRo Llorente, Henar, «El control de la conciencia regia. El confesor real Fray Bernardo de Fresneda», en MartíneZ Millán, José (dir.), La Corte de Felipe II, Madrid, 1998, pp. 149-188.

13. CAVILLAC, Michel, «La reforma de la beneficencia en la España del Siglo XVI: la obra de M. Giginta», Estudios de Historia Social 10-11 (1979) pp. 7-59, p. 53.

14. Pérez Herrera, Cristóbal, Amparo de Pobres, Madrid: Espasa-Calpe, 1975 (edición, introducción y notas de Michel CAVILLAC); CAVILlaC, Michel, «La ‘reformación de los pobres' y el círculo del Doctor Pérez de Herrera (1595-1598)», en MARTíneZ Millán, José (ed.), Flipe II (1598-1998). Europa dividida: la Monarquía Católica de Felipe II (Actas del Congreso Internacional celebrado en la UAM, 20-23 de abril de 1998), pp. 197-204; idem, «Alemán y Guzmán ante la reformación de los vagabundos ociosos», en PiÑERo Ramírez, Pedro M., ed., Atalayas del Guzmán de Alfarache. Seminario interna- 
Mateo Alemán y su Guzmán de Alfarache, obra que para el mencionado hispanista suponía la reafirmación de un proyecto reformista contrario a cualquier parasitismo, mendicante o señorial ${ }^{15}$.

La urgencia política de la jornada real por Aragón no fue ambiente propicio para tratar temas de reformación. Cuando una consulta de Rodrigo Vázquez de Arce, por entonces presidente de Hacienda, llegó a Monzón en octubre de 1585, acerca de las culpas arrojadas por el conde de Orgaz sobre ciertos individuos por prácticas sodomitas, el conde de Barajas recibió orden de tratar el asunto en el Consejo Real, ante la inexistencia de una Junta al efecto ${ }^{16}$. No obstante, como ya aconteciera en la jornada de Portugal, la comitiva real se vio afectada por una epidemia que supuso la muerte de numerosos ministros (entre otros, el marqués de Aguilar, consejero de Estado, Lope de Figueroa, consejero de Guerra, y el secretario Antonio de Eraso). Las Cortes de Monzón terminaron apresuradamente en diciembre de 1585 (tras una breve estancia en Binéfar) y se reavivó, como resultado de todo ello, el siempre presente fatalismo providencialista de Felipe II, especialmente inducido porque entre los fallecidos estaba el arzobispo de Zaragoza, don Andrés Santos, poseedor, según el cronista Cabrera de Córdoba, de las virtudes que para su pueblo deseaba el rey ${ }^{17}$.

Quizá como expresión adicional del deseo regio de gobernar a través de un órgano colegiado, la llamada Junta de Noche, al término de la jornada arreciaron los rumores y denuncias sobre la relajación de costumbres en la Corte, y la defectuosa forma de gestión del Consejo Real, que provocaba una peligrosa acumulación de negociantes en Madrid. Este asunto fue preocupación recurrente en estos años, a la que no se consiguió dar solución. Tales negociantes se dividían entre quienes esperaban la resolución de sus pleitos por el Consejo, quienes creían respaldar sus pretensiones de oficio con su permanencia en la Corte, en busca de la intercesión del Presidente o los ministros de los Consejos, y aquellos otros que simplemente se trasladaban a Madrid desde cualquier lugar en busca del anonimato urbano, para vivir «suelta y viciosamente» ${ }^{18}$. En el primer caso, se extendieron acusaciones contra el conde de Barajas, por no aplicar la ley 17, del título cuarto, libro segundo, de la Nueva Recopilación, que obligaba a que

cional sobre Mateo Alemán..., Sevilla, 2002, pp. 141-165 asimismo, MAZA ZorriLla, Elena, Pobreza y asistencia social en España, siglos XVI al XIX, Valladolid, 1987, pp. 90-96, y MARTZ, Linda, Poverty and welfare in Habsburg Spain, Cambridge University Press, 2009, pp. 86-91.

15. CaVILlac, Michel, Pícaros y mercaderes en el Guzmán de Alfarache. Reformismo burgués y mentalidad aristocrática en la España del Siglo de Oro, Granada, 1994; IDEM, Guzmán de Alfarache y la novela moderna, Madrid: Casa de Velázquez, 2010, especialmente «Los Rostros del Atalaya en el imaginario del Siglo de Oro», pp. 7-22.

16. IVDJ, e. 55, c. 72, carp. 1585, no 29, Felipe II a Mateo Vázquez, 7 de octubre de 1585.

17. Al respecto, CABrera DE CóRDOBA, Luis, Historia de Felipe II. Rey de España, III, Salamanca, Junta de Castilla y León, 1998 (ed. a cargo de José MARTínez MiLlán y Carlos Javier de CARLOS MorALES), p. 1111.

18. AZ, c. $142, \mathrm{n}^{\circ} 201$. 
las causas instruidas en primer lugar, fueran también las primeras en sentenciarse ${ }^{19}$. En cuanto a los pretensores de oficios, en un borrador sobre la reforma de la Cámara, que se preparaba desde el mismo regreso a Madrid, se encargaba al Presidente atender al desalojo de la Corte tanto de beneméritos como de deméritos para los $\operatorname{cargos}^{20}$, en la línea de lo que casi tres años antes demandara Mateo Vázquez.

Pero quizá más fiable que estos testimonios sea el de un personaje llegado a la Corte en 1586, autor de la «Carta de un cortesano de otro t[iem]po que se halló en la calle para un grande q. le escriuió le auisase cómo hallara la Corte y que le parezía della», que ofrece, con humorístico cálamo, un perfil de las licencias de la nobleza cortesana, las ambiciones de los diferentes ministros, los cambios urbanísticos, etc. El panorama palaciego que describe, entre pasivo e incendiario, se completaba a pie de calle por llamativos excesos: «... los uiejos se acuchillan, los moços se afeytan, los grandes q. ay se acuestan muy de mañana y se leuantan en anocheziendo... en resoluçión no e uisto cossa q. no esté mudada ni hombre q. no se ande lamentando. Este es el estado en el q. está la Corte» ${ }^{21}$. Con propósito de contribuir al remedio de la perniciosa superpoblación cortesana, se decidió, además, que cada orden religiosa designara un procurador general que atendiera en la Corte «... todos los negocios del estado de la orden y de los particulares della.... $\rangle^{22}$.

\section{CONVOCATORIA DE LA JUNTA}

Si se valora la relación de tipo familiar, el ascendiente de orden paternal que entonces ejercía el rey sobre la nobleza -al menos en el plano doctrinal-, a la que Felipe II pretendía conferir un valor ejemplar, fue la ociosidad en que se disolvían numerosos títulos, como los marqueses de Cogolludo y de Peñafiel, individuos vinculados al almirante de Castilla (caso de don Diego Enríquez), e incluso grandes de España como el conde de Paredes de Nava, la que decidió al rey a constituir una nueva Junta de Reformación, como refiere el informado Luis Cabrera de Córdoba ${ }^{23}$. En esta determinación influyó así mismo la opinión común acerca de que para ser noble no bastaba con la cuna, sino que la sociedad tenía que reputar como tal al favorecido con esa condición; razón por la que, a la vez, el «vivir noblemente» fue esgrimido en

19. Ibidem, c. $145, \mathrm{n}^{\circ} 65$ y 66; AZ, c. $143, \mathrm{n}^{\circ} 91$. La citada disposición, en Recopilación de las leyes destos reynos, hecha por mandado de la Magestad Católica del Rey don Felipe Segundo nuestro señor:... Año $1640 \ldots$ En Madrid. Por Catalina de Barrio y Angulo. Y Diego Díaz de la Carrera, f. 65r.

20. IVDJ, e. 90 , c. 129 , s.n.

21. BNE (Biblioteca Nacional de España). Ms. (manuscrito), 1761, ff. 251r.-253r.

22. IVDJ, e. 90 , c. $129, \mathrm{n}^{\circ} 519$.

23. CABrera de CórdobA, Luis, Historia de Felipe II, rey de España, III, op. cit., p. 1155. La Junta de Reformación presentó -el 4 de noviembre de 1586- una relación al monarca muy parecida, en la que se detallaban los juegos de dinero que se realizaban en la casa del marqués de Auñón y la prostitución acogida en determinadas casas, entre otros puntos (AZ, 132, $\left.\mathrm{n}^{\circ} 54\right)$. 
muchas ocasiones como esencial en las pruebas de hidalguía ${ }^{24}$. Como escribió Fray Francisco Ortiz Lucio en la dedicatoria de sus Lugares comunes al conde de Chinchón, en 1592, «... la nobleza verdadera, dize la escriptura, ser la que nace y se funda en virtud...» ${ }^{25}$. Fueron las largas ausencias del Rey, y la prohibición de que los nobles jóvenes sirvieran a las damas del Alcázar y entraran en el aposento del Príncipe, los hechos que arrojaron a los nobles a la molicie, opinión en la que, en lo sustancial, coincidían tanto el anónimo corresponsal como Cabrera ${ }^{26}$. Pero la formalización de una nueva junta encargada de estos menesteres estuvo también muy relacionada con otros factores. Los temores del rey a la ira divina se recrudecieron por un factor bien interesado, los renombrados logros del antihispano papa Sixto V en el control de las costumbres sociales ${ }^{27}$, que podían amenazar la pretendida iniciativa de la Monarquía Católica sobre Roma en terreno reformista. Todo ello le condujo a buscar, una vez más, soluciones para erradicar los pecados públicos.

Esta serie de medidas no se arbitraron en vacío, sino que se desarrollaron en un ambiente centrado en la captación del favor divino por vías directas e indirectas. Dado que, como señaló Tarsicio de Azcona, una cosa era el planteamiento teórico y otra la realidad de las costumbres sociales, que influía tanto en los clérigos como en los simples fieles para regirse con llamativa laxitud moral, menudearon obras del tipo de los Tres libros contra el pecado de la simple fornicación, de Francisco Farfán, que

24. Guerrero Mayllo, Ana, Familia y vida cotidiana de una élite de poder: los regidores madrileños en tiempos de Felipe II, Madrid, 1993, p. 6 y las obras aquí citadas.

25. Lugares comunes de la segunda impressión, muy corregida y emendada, con una nueva tabla y compendio de todas las doctrinas, lugares y escripturas, de grande utilidad para todos los estados, especial para Predicadores, Curas y Prelados. Es el autor Fray Francisco Ortiz Luzio, predicador de la provincia de Castilla, de la observancia de Sant Francisco... Impresso en Alcalá de Henares, en casa de Iuan Íñiguez de Lequerica. Año 1592.

26. CABrera DE CóRdobA, Luis, ibidem. También BNE, ms. 1761, ff. 251r.-253r.: «Palacio muy retirado las damas no lo son sino donzellas y las donzellas dueñas y assi no ay terreno ni galanes. La camara del Rey tan retirada como la de su hija, todos quedan hechos democritos».

27. En este terreno, destacó la bula Romanus Pontifex, de 20 de diciembre de 1585, por la que se obligaba a todos los obispos hispanos a visitar Roma cada cuatro años, y entregar una relación sobre el estado de sus diócesis, informes que constituyeron el gran fondo Relationes, a través del que se podía valorar el celo pastoral de cada uno. El propósito de las visitas ad limina, que originaban tales informes, era la reforma del clero y los fieles a partir de la personal de los obispos (TELLECHEA IDÍGORAS, José Ignacio, «Diócesis de Calahorra y Santo Domingo: las relaciones de visitas ad limina (1598-1794)», Anthologica Аnпиа, 38 (1991), pp. 107-201, p. 109; RoBRES LlUCH, Rafael, «La Congregación del Concilio y San Carlos Borromeo en la problemática y curso de la Contrarreforma», Anthologica Annua, 14 (1966), pp. 101-178, p. 177). En la misma línea, Sixto V también emitió sendos motus proprios que obligaban a proveer las parroquias por concurso y darlas al más idóneo y suficiente, lo que haría ver a los beneficiados que el medio más eficaz para conseguir los beneficios sería el estudio y el trabajo, sin dependencia de los cabildos. El primero de ellos fue el Cum de rebus, de 24 de septiembre de 1586, relativo a Calahorra y la Calzada, al que cabe añadir el Sanctum et salutare, de 5 de enero de 1589. Clemente VIII atenuó los efectos de estos documentos legales mediante otro Motu proprio, Moderatio bullae Sixti V contra cléricos male promotos, de 28 de febrero de 1596, TelleCHEA IDÍGORAS, José Ignacio, op. cit., p. 119. 
encargaban la conciencia del lector sobre el desenfreno en este ámbito ${ }^{28}$; al tiempo que convertía a Felipe II (a quien dedicaba la obra) en mero instrumento de Dios, «en cuya mano anda siempre el coraçón del rey para guialle donde es su voluntad ${ }^{29}$. A su vez, en los medios oficiales se apreció una mayor conciencia tanto de la esencia oral y colectiva de la predicación, como de su calidad transmisora de la tradición canónica y el conjunto de valores propios de la política confesionalista ${ }^{30}$. Conforme con ello fue la aparición coetánea de obras sobre el modo de predicar, caso de las Comparaciones o símiles para los vicios y virtudes, de Juan Pérez de Moya, aparecida en 1584, en la que escribió elocuentemente: «...el predicador que acostumbra a predicar cosas especulativas e ingeniosas, y no trata de reprender los vicios del pueblo, hará poco provecho y allegará pocas mieses en las trojes de su señor» ${ }^{31}$.

Igualmente, la época inmediatamente anterior al comienzo de las reuniones de la junta fue un momento de furia deprecativa, visible en el continuo encargo de elevación de plegarias por parte de la Corona a prelados y órdenes religiosas ${ }^{32}$. Factores adicionales a los ya citados, como el grave daño causado por la epidemia de viruela iniciada en 1585, propiciaron una concomitancia entre las autoridades eclesiásticas a la hora de responder a esta solicitud regia. El 17 de abril de 1586, Alonso de Revenga, deán de Sevilla, se dirigía a Mateo Vázquez con el parabien por concluir la jornada de Monzón y la solicitud de recordar al rey «... continúe el escrebir al deán y cabildo desta $\mathrm{s}$ [an]ta como lo ha hecho quando nos mandare que se agan sacrificios y plegarias pues la mucha voluntad con que es obedeçido ayuda para que se nos haga este fauor...» ${ }^{33}$. Unos días después, fray Juan de las Cuevas, general de los dominicos, acusaba recibo de la carta real echada en falta por el deán de Sevilla, «... en que me

28. AzConA, Tarsicio de, «Reforma del episcopado y del clero de España en tiempo de los Reyes Católicos y de Carlos V (1475-1558)», en García Villoslada, Ricardo (dir.), Historia de la Iglesia en España, III-1 ${ }^{\circ}$, Madrid, 1980, pp. 153-173.

29. FARFÁn, Francisco, Tres libros contra el peccado de la simple fornicación: donde se averigua, que la torpeza entre solteros es peccado mortal, según ley divina, natural y humana: y se responde a los engaños de los que dizen que no es peccado... En Salamanca, por los herederos de Matthías Gast. Año 1585. De modo muy semejante, el doctor Juan Roa Dávila afirmaría que «... el corazón del rey está en la mano de Yahvé, y Este lo dirigirá a dónde le plazca» (ROA DÁvILA, Juan, De Regnorum Iustitia o el control democrático, ed. crítica bilingüe por Luciano Pereña, Madrid, 1970, p. 8).

30. BELO, André, História \& Livro e Leitura, Belo Horizonte, 2002, p. 57, y las obras allí citadas.

31. PÉREZ DE MoYA, Juan, Comparaciones o símiles para los vicios y virtudes. Philosofía Secreta, Madrid, 1996, pp. XIX-XX. Que existía un ambiente y un mercado propicios para tales materias lo señala el curioso cambio de temática que por entonces realizó Pérez de Moya, quien abandonó los tratados matemáticos por la literatura moralizante. En 1583 ya había aparecido en Madrid su Varia Historia de sanctas e illustres mugeres... (op. cit., p. X).

32. BL (British Library). Add. (Additional) 28.263, ff. 376r.-377r., en RIBA, Carlos, Correspondencia privada de Felipe II con su Secretario Mateo Vázquez 1567-1591, Madrid, 1959, pp. 371-372, Mateo Vázquez al rey y su respuesta, 5 de abril de 1586; IVDJ, e. 90, c. 128, n²44, García de Loaysa a Mateo Vázquez, 16 de abril de 1586.

33. AZ, c. $150, \mathrm{n}^{\circ} 2$. 
manda haga encomendar a Dios en esta prouincia de Castilla de la orden de n[uest]ro padre Santo Domingo las necesidades y trabajos de la República que al presente se padecen...», y detallaba las decisiones adoptadas al respecto ${ }^{34}$. Incluso la pragmática de los Tratamientos y Cortesías, publicada en octubre de ese año ${ }^{35}$, apareció claramente influida por este ambiente general de atracción de la voluntad de Dios, mediante el cultivo de valores tan cristianos como la moderación y la modestia.

Bastó la respuesta del Conde de Barajas a sendos memoriales que detallaban los referidos excesos para que en julio de 1586 le ordenara consultarlos con el arzobispo de Toledo Quiroga y el confesor Chaves, de la forma más discreta, «en algun monast[eri]o o otra parte, que no sea en palacio porque se trate con la más dissimulacion q. se pueda ${ }^{36}$. Si la presencia del confesor, en cuya posada se realizaban las reuniones ${ }^{37}$, correspondía a su notorio protagonismo en la política confesionalista del Rey, de modo que era él quien comunicaba a los afectados las resoluciones de la Junta, la inclusión del Cardenal Quiroga se dirigió a otorgar mayor eficacia al comité mediante la adición de su jurisdicción eclesiástica a la seglar del presidente Barajas, para así evitar las discusiones sobre competencias que habían entorpecido la Junta de $1579^{38}$. La misma voluntad de superación de las dificultades que vararon la Junta anterior supuso la explícita atribución de la ejecución de sus acuerdos a los alcaldes de Casa y Corte, cada uno de los cuales enviaría relación de sus rondas a la Junta ${ }^{39}$. Así como la convocatoria de una reunión semanal, dado que el furor del presidente Pazos en convocar reuniones había provocado que la Junta precedente dejara de reunirse, por la falta de asuntos que considerar. En esta ocasión, Felipe II poseía, a priori, un decidido empeño en conseguir logros en la materia.

Así pues, comenzaron las reuniones de la Junta. El arzobispo Quiroga abogó por el nombramiento de un nuevo visitador de la Corte y todos sus miembros acordaron que amonestara por sus excesos en el juego, entre otros, al almirante de Castilla, los duques de Medinaceli, Nájera y Feria, al conde de Lemos, al prior don Fernando y don Diego Enríquez, en quien concurría, además, el protagonismo de escandalosos

34. IVDJ, e. 90, c. 129, $\mathrm{n}^{\circ}$ 661, carta de fray Juan de las Cuevas al rey, 25 de abril de 1586.

35. MARTínEZ Millán, José, «El control de las normas cortesanas y la elaboración de la pragmáica de Cortesías (1586)», Edad de Oro,18 (1999), pp. 103-133.

36. AZ, c. 147, $\mathrm{n}^{\circ}$ 220. La presencia del arzobispo de Toledo en este comité es mencionada por BoYD, Maurice, Cardinal Quiroga, inquisitor general of Spain, Dubuque, 1954, p. 36. Sobre su gran importancia política, PiZARro Llorente, Henar, Un gran patrón en la corte de Felipe II: don Gaspar de Quiroga, 2004.

37. Ibidem, $\mathrm{n}^{\circ}$ 53, Presidente Barajas a Felipe II, 24 de agosto de 1586: «Esta tarde nos bolvimos a juntar en la posada del confessor, el Cardenal de Toledo y el y yo...».

38. Ibidem, $\mathrm{n}^{\circ}$ 220, orden de convocatoria de la Junta, Mateo Vázquez a Barajas, julio de 1586. «... y spera $\mathrm{Su} \mathrm{Md}$. q. juntas las jurisdictiones ecclesiastica y seglar, haziendo el S[eñ]or Card[ena]l por su parte lo que le toca, y V.S.I. lo que le toca por la suya, con las veras que se deve y conviene como lo confia de Vas. S[eñorí]as Ill[ustrisi]mas y se lo encarga sea lo q. se hiziere de mucho effecto».

39. IVDJ, e. 62, c. 83, n 319, Presidente Barajas a Felipe II, 30 de octubre de 1586. El Rey insistió en que además de enviar estas relaciones se castigara a los culpados en ellas. 
deleites venereos con la condesa de Valencia; hechos por los que fue desterrado de la Corte. Llevados por el interés en proteger el honor de la Condesa, los miembros de la Junta mantuvieron oculto el repetido trato ilícito de Enríquez con ella, y por eso no se justificó su condena por el verdadero motivo (su participación en una trifulca en la que el conde de Valencia le asestó varias cuchilladas); sino por recoger en su casa mujeres desterradas con el mismo objeto de acceder sexualmente a ellas. En el caso intervino también Cristóbal de Moura - quien desde la incorporación de Portugal había ascendido en la gracia real hasta formar parte de la Junta de Noche-, que abogó por encargar al padre confesor la comunicación de la pena de un año de destierro a más de treinta leguas de la Corte para don Diego y su mujer; pues, conocida la discreción del confesor real, «por este camyno se encubrirya mejor la falta de aquella señora...». En obediencia de esta prevención, Chaves requirió a Enríquez el cumplimiento de la pena en Lisboa, hasta que recibiera nueva orden del rey ${ }^{40}$.

Como se aprecia, la Junta destilaba la consideración confesional de la mujer como ente irresponsable digno de protección, y criatura predispuesta naturalmente hacia el pecado. Nótese especialmente el injusto destino de la mujer de Enríquez, abocada al destierro por culpa ajena. En el mismo sentido, mientras Barajas encarecía a los alcaldes, por un lado, y al corregidor y su teniente, por otro, la necesidad de que cumplieran los acuerdos de la Junta, se fue elaborando relación de las señoras y otras mujeres viudas, solteras o casadas que vivían «escandalosamente». La imagen de la mujer como incitadora al pecado, que el clero trataba de inculcar al pueblo estuvo especialmente presente tanto en el Rey como en los ministros comprometidos con su política, especialmente los tonsurados, por lo que a propuesta de Felipe II se trató también de «los rebozos y cubiertas del rostro con los mantos por parte de las mujeres... q. ha mostrado la experiencia lo han sido para muchos males», y su afición a negociar con los ministros ${ }^{41}$. Las discusiones que embargaron entonces a Consejo Real y Junta de Reformación sobre la pertinencia de elaborar ley que prohibiera a las mujeres andar con los rostros ocultos, muestran la transcendencia de materias de tal jaez en sistemas confesionalistas donde la observancia de las normas dictadas por Trento fomentaba la estabilidad social ${ }^{42}$; pero también la indeterminación jurisdiccional propia del sistema político vigente, que amenazaba con inutilizar el medio arbitrado (la Junta) para superar la secular falta de despacho de los Consejos. Sólo cuando la Junta votó por no hacer ley, el Conde-Presidente refirió en ella cómo el Consejo Real había alcanzado la misma conclusión ${ }^{43}$, al valorar los inconvenientes que tendría que un alguacil proce-

40. AZ, c. $147, \mathrm{n}^{\circ} 53$, reunión del 24 de agosto de 1586.

41. Ibidem. Los manuales de confesores de la época identificaban mujer con pecado. SARRIÓN MORA, Adelina, Sexualidad y confesión: la solicitación ante el Tribunal del Santo Oficio (siglos XVI-XIX), Madrid, 1994, pp. 39-56.

42. SARrión MORA, Adelina, op. cit., pp. 12-13.

43. AZ, c. 147, $\mathrm{n}^{\circ}$ 270, reunión de la Junta de Reformación de 4 de septiembre de 1586; Ibidem, $\mathrm{n}^{\circ} 271$, parecer de Juan Tomás. 
diese a destapar el rostro a aquellas mujeres que andaban con él tapado a espaldas de sus maridos.

De modo que la cuestión estaba impregnada de la complejidad propia de los juicios apriorísticos de intenciones. Las discusiones en torno a disposiciones legislativas sobre el uso del velo prejuzgaban, como vemos, una actitud por parte de quien lo usaba. El problema era que no se legislaba sobre un objeto y su uso, sino sobre algo tan intangible o arbitrario como la intención que la mujer, entendida como género ${ }^{44}$, tenía al utilizarlo. Esto se advirtió con claridad en el voto particular que sobre la cuestión presentó el licenciado Juan Tomás, oidor del Consejo, de gran predicamento en la Corte mediada la década de 1580, quien votó que la ley se hiciera sólo tras comprobar las ventajas y perjuicios de su aplicación mediante pregón de los alcaldes, que ordenara a las mujeres llevar descubiertos los rostros. Dado que, en su opinión, «... el andar atapados los rostros es cosa ocasionada para que mugeres no muy concertadas se atreuan a cosas ruines que podrían cessar quitándoles la occasión». Además de que también existían aquellas mujeres que «con industria dexan sólo el un ojo de fuera q. a mi parecer parece aquello soltura y libertad, o liberalidad muy contraria a la honestidad q. las mugeres deuen tener». Por no entrar a valorar las misas, sermones, confesiones, estaciones y hospitales que dejarían de visitar aquellas que se tapaban el rostro sólo porque sus semejantes no identificasen a la portadora de un hábito pobre y raído; o las misas que perderían numerosos hijos por evitar sus madres el acoso por los galanes, o por no tener la variedad de vestidos conveniente a sus personas ${ }^{45}$. Con todo, los velos fueron prohibidos por capítulo de las Cortes que por entonces se celebraban, publicado cuatro años después ${ }^{46}$.

\section{DESARROLLO DE LA JUNTA}

Por entonces, Felipe II parecía más atento que de costumbre a las cuestiones de reformación. Ansiaba recibir noticias sobre la misión encomendada a visitadores y curas en la Corte, donde la concurrencia de naturales de numerosas naciones hacía peligrar las medidas emprendidas ${ }^{47}$. Quizá por ello el Conde de Barajas informaba

44. Aval, por lo tanto, para el enfoque de género de la historia de las mujeres: ORTEGA, Margarita, «Una reflexión sobre la Historia de las Mujeres en la Edad Moderna», Norba, 8-9 (1987-88), pp. 159-168; BirRIEl SAlCEDO, Margarita $\mathrm{M}^{\mathrm{a}}$, «Mujeres y género en la España del Siglo de Oro», en MARTíNEZ Berbel, Juan Antonio; CASTILla PÉREZ, Roberto, eds., Las mujeres en la sociedad española del Siglo de Oro: ficción teatral y realidad histórica, Granada, 1998, pp. 37-55.

45. AZ. C. 147, n 271, Voto de Juan Thomás, 10 de septiembre de 1586.

46. LEÓN PINELO, Antonio de, Velos antiguos i modernos en los rostros de las mugeres: sus conuenencias $i$ daños: ilustracion de la Real Prematica de las tapadas. En Madrid: por Iuan Sánchez, 1641.

47. En este sentido, ante los excesos cometidos por la justicia cortesana sobre naturales del reino luso (muy numerosos desde la anexión de 1580), el flamante Consejo de Portugal propuso exitosamente en 1584 la asignación exclusiva de aquellas causas que implicasen a oriundos de ese reino a uno de los alcaldes de Casa y Corte. Esto implicaba una curiosa mezcla de jurisdicción privativa y acumulativa en tales ministros, significados por la entidad comisional de gran parte de su labor (Cfr. BA (Biblioteca de Ajuda, Lisboa). Ms. 51/X/9, f. 168r.-v.). 
de la celebración de las reuniones pese a que no se llegara en ellas a ninguna decisión, «para que U. M[ajesta]d. entienda que no ay descuido en el proseguirla» ${ }^{48}$. Tales informes referían la revisión de las relaciones de las rondas de los alcaldes de Casa y Corte, con el continuo propósito de obviar los inconvenientes que habían anquilosado la Junta precedente, reducidos principalmente a la falta de ejecutividad ${ }^{49}$. Ello calmaba las ansias regias por recibir noticias de la referida misión, pero a su vez le llevó a encarecer la necesidad de complementarla con el castigo efectivo de las culpas advertidas en el curso de tales rondas.

El rey aprovechaba estos recesos para someter a la Junta asuntos como la representación de comedias en los monasterios de monjas y frailes, que en su opinión atentaban contra el necesario recato de aquellas casas ${ }^{50}$. Dado que, si en muchas ocasiones los actores eran ajenos al instituto religioso, en otras «tambien las monjas las hazen allá dentro dexando el sancto hábito de su professión y vistiéndose galas y paños profanos $\rangle^{51}$. Con esta solicitud, Felipe II mostraba estar muy al corriente de las controversias en torno a materia teatral, pues ya el franciscano Juan de Pineda había arremetido en 1581 contra las representaciones en los conventos ${ }^{52}$. La Junta optó por la discreción, para no dañar el decoro de los religiosos, y encargó nuevamente al confesor Chaves escribir sobre la necesaria prohibición de estas representaciones a los provinciales de las Órdenes. Esta ronda de misivas comenzaría por establecimientos especialmente notados por incurrir en el abuso, como el monasterio de Santa Clara de Madrid y los conventos de Bernardas. Las respuestas serían revisadas en la Junta ${ }^{53}$.

A juzgar por la rápida tramitación de los acuerdos de la Junta, y el decidido empleo de los alcaldes de Casa y Corte como ejecutores de sus decisiones, cabe aventurar que estaba resultando más eficaz que la precedente. En este sentido, no resulta casual la coincidencia de su constitución con la discusión de otro tipo de medidas más ejecutivas, y de evidente complementariedad, como elevar el número de alguaciles,

48. IVDJ, e. 62, c. 83, no 319, Barajas a Felipe II, 30 de octubre de 1586.

49. Ibidem. Remitieron a Felipe II una relación del alcalde Espinosa, «para si U. Md. se siruiere de saber cómo anda lo de las rondas...».

50. Ibidem, «Con daño de la simplicidad, y sanctidad de costumbres, que las personas dedicadas a nro. sr. han de tener, porque la trama de las comedias, digo de muchas dellas o es de amores o tienen entremeses que lo son, cuyas imagines dan despues desabrimiento al alma que ha de ser la q. se sabe, que deve ser, en el choro, claustro, y dormitorio...».

51. Ibidem, respuesta del Rey de 1 de noviembre de 1586.

52. PinedA, Fray Juan de, Diálogos familiares de la Agricultura Christiana, Madrid, 1963, pp. 161-164, apud SuÁREZ GARCÍA, José Luis, «La licitud del teatro en el reinado de Felipe II: textos y pretextos», en Pedraza Jiménez, Felipe B., GonzÁlez CAÑAl, Rafael, El teatro en tiempos de Felipe II, UCLMFestival de Almagro, 1999, pp. 219-251, p. 222.

53. Por ejemplo, IVDJ, e. 90 , c. $128, \mathrm{n}^{\circ}$ 380. El confesor Chaves al General de los franciscanos, con la prohibición de que «... ni agora, ni de aqui adelante, en ninguno de los conventos de monjas de la orden de U[uestra] P[aternida]d se representen los tales auctos y comedias, no solamente dentro de los monasterios (que esto en ninguna manera se puede permitir) pero ni tampoco en el cuerpo de la Yglesia ni en otra parte de la casa...». 
coincidiendo con una renovación de los ostentadores de estas varas. Proposición defendida ardientemente por el presidente Barajas, en su doble condición de Presidente y miembro de la Junta. Como ya se había ordenado infructuosamente que alguno de los 38 alguaciles sirviera anualmente en lo criminal, propuso la creación de ocho o diez alguaciles que se ocuparan de estos casos, «considerando la necess[ida]d grande que ay de remediar los daños de la Corte, y muchedumbre de gente viciosa y vagamunda q. ay en ella». Ministros que, para ayudar al propósito para el que eran creados, estarían exentos de acompañar a los alcaldes de día, para hacerlo de noche en sus rondas, y acudir a primera hora a las visitas de cárcel a dar cuenta de lo ofrecido; así como de ausentarse de la Corte y asistir a la guarda de Palacio.

Su propuesta de que estas plazas fueran ocupadas según los méritos de los candidatos, sin atender a las recomendaciones ${ }^{54}$ debe entenderse como manifestación de la carencia -o modestia- de una red clientelar sólida por parte del Conde. Puesto que los otros ministros que intervinieron en este asunto, instalados más firmemente en la gracia real, bien a través de la intervención en la Junta de Noche que iba consolidándose (como el conde de Chinchón), bien ocupándose del manejo de la hacienda o efectuando propuestas de letrados (como Rodrigo Vázquez), sí hicieron extensa relación de sus clientes para ocupar esos cargos. Se mostraban así, si no más conscientes que Barajas del valor de las relaciones de patronazgo como fundamento del sistema político, sí más pertrechados de apoyos humanos para valerse en tal sistema. Si el conde de Chinchón limitó a seis el número de nuevas provisiones, y por un periodo de dos años, Vázquez de Arce fijó en cuatro los alguaciles de lo criminal que debían ser provistos, y en dos el número de alguaciles «del campo». Como quiera que todavía no presidía el presidente de Castilla en la Cámara, pese a su asistencia con los camaristas Juan Tomás y Villafañe, el secretario Juan Vázquez de Salazar terminó por consultar, con acuerdo de los citados, sobre la provisión de tres o cuatro alguaciles «para lo criminal» ${ }^{55}$. Medidas como ésta eran necesarias a juzgar por los desórdenes que, pese a llevar funcionando la Junta desde el verano, seguía protagonizando la nobleza y algún servidor real. Aunque habían sido ya amonestados por el confesor Chaves, el duque de Feria seguía incurriendo en el juego "y otros entretenimientos indecentes», mientras la mujer del relator Baños persistía en la «suelta manera de vivir q. en su casa se tiene con mucho excesso y publicidad». En ambos casos el rey suscribió la propuesta de la Junta de que el confesor repitiera amonestaciones más vehementes.

Al secretario Mateo Vázquez parecieron disgustarle las amplias potestades de Fray Diego de Chaves, y del conjunto de la Junta de Reformación, en materia que limitaba su propia capacidad de manipulación del temor providencialista del rey, de la

54. AZ, c. $146, \mathrm{n}^{\mathrm{o}} 214$.

55. Ibidem. Guiado por el mismo interés de dar mayor atención a las causas criminales el Conde obtuvo del Consejo auto de 28 de julio de 1586, para que cuando en la sala de alcaldes que conocía de lo criminal faltara número para conocer de estas causas, fueran vistas por el alcalde más antiguo de lo civil que tuviera título para lo criminal, Autos y acuerdos del Conseio, de que se halla memoria en los libros, desde el año de 1532 hasta el presente de 618..., En Madrid. Por Luis Sánchez... 1618, f. 25r. (Auto 98). 
que tanto partido político había sacado. Si ya se había inmiscuido en el caso de Diego Enríquez ${ }^{56}$, no dudó después en emplear su vieja táctica: encarecer los graves castigos que Dios impondría a Castilla de no remediar los pecados públicos, erigiéndose con sus propuestas en el salvador de la inquietud regia. Cuando su viejo amigo Lara de Buiza le refirió el estrecho trato al que se acogían sores y seglares entre los muros de monasterio dominico de $\mathrm{Lugo}^{57}$, propuso escribir de nuevo a todos los prelados y justicias sobre el castigo y enmienda de los pecados públicos y someter al Consejo Real el caso. Pese a que éste, como otro acontecido en Almagro, asustó sobremanera al rey, del consejo del secretario sólo suscribió el encargo a los obispos del cuidado de los pecados públicos, que encomendó al propio Mateo Vázquez, asistido por Juan de Idíaquez. Puesto que encargó la indagación de lo sucedido en Lugo a la Junta de Reformación, prosiguiendo su voluntad de supeditar al Consejo «donde nunca se acaba nada y se holvida luego» ${ }^{58}$. Si en este caso concreto la ira del rey venía dada por motivos como su persistente retraso en continuar con la reducción de hospitales, no sería dificultoso hacer numerosa relación de reacciones del monarca en el mismo sentido a consecuencia del defectuoso expediente del Consejo por entonces. Guiada por el interés de respetar la jurisdicción eclesiástica, en postergación de la complementariedad de ambos brazos que acompañara su constitución, la Junta abogó por detraer del conocimiento a Lara de Buiza, y entregar las averiguaciones contra las monjas al vicario provincial o al provincial de los dominicos (a quien escribiría como siempre el confesor encareciéndole el castigo del exceso), y buscó la forma de castigar a los seglares involucrados ${ }^{59}$. Pese a todo el rey siguió pidiendo al secretario Mateo Vázquez que le propusiera respuestas a lo planteado por el conde de Barajas en asuntos de Reformación ${ }^{60}$.

\section{SÚBITO FINAL}

Dado el protagonismo que Felipe II confería al secretario en el tráfago administrativo, su actitud no debió ser beneficiosa para la continuidad de la Junta. Súbitamente dejamos de tener constancia de sus reuniones, con nombre de tal Junta de Reformación, a finales de 1586, sin saber los motivos a ciencia cierta. Parece poco probable que el cese de sus reuniones se debiera al cumplimiento de sus objetivos; más creíble resulta pensar en la irrupción de otras prioridades políticas y, sobre todo, en discrepancias de

56. BL, Add. 28.371, ff. 40-1, en RIBA, Carlos, Correspondencia privada de Felipe II con su Secretario Mateo Vázquez..., op. cit., pp. 408-9, Mateo Vázquez al Rey y su respuesta, San Lorenzo, 2 de septiembre de 1586.

57. Lo más curioso es que Lara, durante su ejercicio previo como alcalde de la Cuadra de Sevilla, fue abiertamente acusado de no hacer vida marital y relacionarse con prostitutas a las que daba cobijo y protección, al tiempo que sus estancias estaban decoradas con pinturas de desnudos. Según estos cargos, no permitía que «hubiese ejecución de justicia en lo tocante a mugeres perjudiciales a la república», MÉNDEZ RODRÍGUEZ, Luis, Velázquez y la cultura sevillana, Sevilla, 2005, pp. 147-148.

58. IVDJ, e. 90 , c. $128, \mathrm{n}^{\text {o }} 309$.

59. Ibidem, e. 21 , c. $31, \mathrm{n}^{\circ} 312$, Barajas a Felipe II, 16 de noviembre de 1586.

60. Ibidem, e. 55, c. 72, cuad. 1586, n 159. Felipe II a Mateo Vázquez, 16 de noviembre de 1586. 
orden faccional entre sus miembros. Puesto que en una de sus últimas reuniones se leyó una relación del alcalde Espinosa, de oscura intención, que decía haber encarcelado a un repostero de Quiroga por amancebamiento, provocando una airada reacción en el cardenal ${ }^{61}$.

Aunque estos tres ministros se volvieran a reunir para tratar asuntos más o menos relacionados con la reformación, durante el resto del reinado de Felipe II no volvería a celebrarse una Junta específica para abordar esta materia de forma unitaria, sometida desde entonces a la múltiple intervención de personajes de influencia política creciente, como García de Loaysa, y del Consejo Real. Pese a la decidida voluntad del rey por conseguir la resolución de estos asuntos, la urgencia política, que obligaba a atender otros surgidos de forma espontánea, volvió a acabar con las reuniones de la Junta de Reformación, como ya aconteciera en 1579, cuyos logros, a juzgar por la situación en la Corte a su repentina conclusión, fueron escasos. Desde comienzos de 1587 este tipo de materias retornó a su cauce formal y se diligenció primordialmente a través de los alcaldes de Casa y Corte y el Consejo Real, si bien es cierto que siguieron teniendo lugar reuniones entre el conde de Barajas y el confesor Chaves para tratar asuntos concretos, y en ocasiones el propio arzobispo de Toledo, sin denominarse a este espontáneo comité Junta de Reformación como tal. El rasgo más destacable de esta nueva etapa fue la abierta intervención en este campo de la Junta de Noche, así como el paulatino protagonismo en él de García de Loaysa. La función del capellán y limosnero mayor congraciaba con la importancia concedida a la atracción del favor divino en un sistema confesionalista, y por ello Miguel Giginta le dedicó en 1587 su Atalaya de pobres, «para que atalaye y vea dónde hay pobres con necesidad de remedio, y se lo procure con Su Majestad ${ }^{62}$. No sería el único autor que, consciente de esta función, le dedicara por entonces una obra, dado que el ya mencionado Francisco Farfán hizo lo propio con su Regimiento de castos y remedio de torpes en $1590^{63}$.

La desaparición de la Junta no supuso obviamente la de aquellas controversias que la originaron, que presentan una llamativa pervivencia en el devenir político de la Monarquía Hispana, hasta el punto de quedar convertidas en expresiones costumbristas de la politica de reformación. En primer lugar, no hubo que esperar mucho para que, en su línea, Mateo Vázquez denunciara «el estar la Corte llena de gente» e hiciera ver al rey la conveniencia de solicitar al Presidente estrecha cuenta de su labor al respecto ${ }^{64}$.

61. IVDJ, e. 21, c. 31, n 312, Barajas a Felipe II, 16 de noviembre de 1586. Quiroga era patrón del partido papista, PiZARro Llorente, Henar, op. cit.

62. CAVILlaC, Michel, «La reforma de la beneficencia en la España del Siglo XVI...», p. 53.

63. FARFÁN, Francisco, Regimiento de castos y remedio de torpes. Donde se ponen XXVIII remedios contra el pecado de la torpeza: y por otras tantas vías se exhorta el christiano al amor de la castidad... En Salamanca:... En casa de Cornelio Bonardo, 1590.

64. AZ, c. 142, nº 201, Mateo Vázquez a Felipe II, 22 de enero de 1587: «La causa principal de estar la Corte más llena de gente q. nunca, dizen unos q. es sperar a ser despachados, y otros el uenirse aquí confiando q. sin temor de ser castigados, podrán uiuir suelta y uiçiosam[en]te, no sé cómo los al[ca]ldes no attienden mucho a esto, y es menester q. lo hagan, y q. el c[on]de de Barajas se lo mande apretadam[en]te y de ordin[ari]o les uaya pidiendo quenta de lo q. hizieren». 
Igualmente, la Junta de Gobierno se ocuparía en abril de 1596 de la «reformación de la gente ociosa de la Corte ${ }^{65}$. En cuanto a las comedias, la pretendida erradicación de las mujeres de las tablas mantenida por la Junta topó con los intereses de los administradores de las cofradías de la Corte, que se mantenían del rendimiento de las primeras, y quedó en suspenso en junio de $1587^{66}$. El rey mostraría el 31 de octubre de ese mismo año su posición favorable a la representación de muchachos en hábito de mujeres (siempre que fuese sin maquillar) y de mujeres en hábito de hombres (siempre que estuviesen acompañadas de sus maridos ${ }^{67}$. Con ocasión de la muerte de doña Catalina Micaela en noviembre de 1597, García de Loaysa participó con Fray Diego de Yepes y Fray Gaspar de Córdoba en un dictamen condenatorio de las comedias que implicó su suspensión. Previamente, el Consejo había prohibido la presencia de mujeres en escena. Pero, como refirió Diego Vique, caballero del hábito de Alcántara y señor de Llauri, «todo aquel nublado se resoluió en dar a las comediantas cierto traje de baquerillos para quando hvuiessen de representar de hombres, y aún este decreto se desvaneció por leve.... ${ }^{68}$. La materia teatral giraría en adelante sobre los mismos temas, especialmente durante el reinado de Felipe IV, en el que a las Ordenanzas de 1644 en corrección de abusos, siguió la suspensión temporal de las comedias en tres etapas distintas: tras la muerte de doña Isabel de Borbón, entre 1646 y 1649, y con ocasión de la muerte del rey ${ }^{69}$.

Finalmente, la cuestión de las tapadas presentó en adelante una llamativa recurrencia, puesto que la obligatoriedad de que las mujeres fuesen descubiertas recibió cobertura legal por disposiciones de 1590, 1594, 1600 y 1639 y dio origen a un sesudo tratado de León Pinelo ${ }^{70}$; que, si bien avalaba esta posición, trataba sobre todo de salvar los escrúpulos de conciencia de la protectora de su libro, doña María de Avellaneda, condesa de Castrillo: «El cubrirse las mugeres los rostros con los mantos echados sin afectación, invención ni artificio, es lícito, honesto i se debe permitir, donde no huviere ley que disponga lo contrario» ${ }^{71}$. Se distinguía así entre castas cubiertas y lascivas tapadas, del modo que ya anticipara el licenciado Juan Tomás en 1586. Persistía un juicio institucional de intenciones sobre el género femenino.

65. IVDJ, e. 45, c. 58, n⿳ 151, reunión de la Junta de Gobierno de 5 de abril de 1596.

66. SANZ AyÁn, Carmen, «Actor», voz en CASA, Frank P.; GARCÍA LOREnZO, Luciano; VegA GARCíALuengos, Germán, Diccionario de la comedia del Siglo de Oro, Madrid, 2002, p. 3.

67. IVDJ, e. 21 , c. $31, \mathrm{n}^{\mathrm{o}} 320$.

68. Ibidem, ms. 26-II-12, f. 87r.

69. Suárez García, José Luis, «Licitud», voz en Casa, Frank P.; García Lorenzo, Luciano; Vega GARCÍA-LuENGOS, Germán, op. cit., p. 195.

70. LEÓn Pinelo, Antonio de, Velos antiguos i modernos..., op. cit.

71. Op. cit., f. 127v. La obra es objeto de análisis en DonÉZAR DíEZ DE UlzURRUn, Javier M. SANTOLAYA HEREDERO, Laura, «Una cuestión política interna en el reinado de Felipe IV: si las mujeres deben usar velo o no», Espacio, Tiempo y Forma, Serie IV, Historia Moderna, 8 (1995), pp. 133-153. 